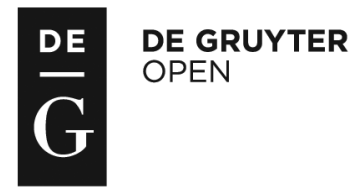

Administration, vol. 64, no. 1 (2016), pp. 29-60

doi: 10.1515/admin-2016-0010

\title{
Analysis of recent property price developments and implications for Local Property Tax liabilities and revenue yield
}

\author{
Brendan O'Connor \& Donal Lynch \\ Economics Division, Department of Finance
}

\begin{abstract}
The introduction of the Local Property Tax (LPT) in 2013 marked a significant reform to tax policy in Ireland. Initial liabilities for LPT were determined by self-assessment into bands of property values as of May 2013, and the first revaluation was initially scheduled for November 2016. Reflecting the significant residential property price growth which has occurred since the initial valuation date, this paper estimates the implications for LPT liabilities of a hypothetical revaluation at May 2015 property prices. Drawing on a range of data sources, the authors use a transition matrix approach to illustrate the likely changes in LPT valuation bands and liabilities for residential properties. Revaluation is estimated to significantly increase tax liabilities for some taxpayers, with properties in higher valuation bands in May 2013 incurring larger increases in liability. The analysis also indicates substantial regional variation in band changes, with the largest band movements mainly occurring in Dublin.
\end{abstract}

Keywords: Local Property Tax, property price changes, residential property, tax liabilities, Thornhill review 


\section{Introduction}

In 2015 Dr Don Thornhill was asked by the Minister for Finance to conduct a review to consider the operation of the Local Property Tax (LPT) and, in particular, any impacts on LPT liabilities due to property price developments, and to make recommendations in relation to issues that arose from the review (Thornhill, 2015). The review was finalised in July 2015.

The analysis and findings set out in this paper were produced by the authors as part of the Thornhill review and with respect to price changes up to May 2015. This paper sets out estimates of the potential implications for taxpayer liabilities of property price developments since the first market-value estimates for LPT purposes were made in May 2013.

Over the period from May 2013 to May 2015, property prices increased nationally by 26 per cent, according to the Residential Property Price Index (RPPI) produced by the Central Statistics Office (CSO). This overall increase masks considerable regional variation: prices in Dublin increased by approximately 41 per cent while properties outside of Dublin increased by 14 per cent.

Taxpayer filings made to the Revenue Commissioners in May 2013 provide information on the number of properties within each LPT valuation band. However, the filings do not provide the exact market values at that time as taxpayers were only asked to place their property within a valuation band.

While there is no single source of data on actual property values in May 2013, we use a range of sources to estimate a representative sample of market values at that time. We take account of changes in property prices by rolling forward these values based on price developments since the original valuation period. The implications of these price changes for taxpayer liabilities can then be estimated.

On the basis of this approach, we estimate that if a revaluation were to take place based on price changes up to May 2015:

- 48 per cent of properties would remain in their original valuation band;

- 35 per cent of properties would move up by one valuation band;

- 10 per cent of properties would move up by two bands; and

- the remainder would move up by between three and six valuation bands. 
This indicates that if a revaluation were to occur based on these changes there would be significant increases in tax liabilities for some taxpayers, with properties in the higher valuation bands in May 2013 experiencing the largest number of band movements. The analysis also indicates a wide degree of regional variation in band changes, with the largest movements in bands mainly occurring in the Dublin area.

This report continues as follows:

- First, recent price developments and available data in the property sector are discussed. An estimation methodology is then described that is used to generate a sample of property values in May 2013, which are then assigned to valuation bands for comparison with selfassessed taxpayer filings made to the Revenue Commissioners.

- Next, property values are rolled forward from May 2013 prices based on market trends, and the implications for taxpayer liabilities are considered.

- Finally, the possible impact of property price changes for LPT revenue is estimated.

\section{Property price developments and data}

This section discusses the two main sources of data on property price developments, namely the Residential Property Price Index and the Residential Property Price Register, and describes a method that uses these data sources to construct a sample of property prices in May 2013, the point in time used for LPT valuation purposes.

\section{Residential Property Price Index}

Changes in residential property prices are provided by the CSO through the monthly RPPI, which reports property price changes by type - i.e. houses and apartments - both on a national basis and for Dublin. A sub-index for national price developments excluding Dublin is also produced. ${ }^{1}$

The RPPI is a hedonic, Laspeyres-type index constructed on the basis of mortgage drawdowns, and as such does not include residential property purchases by cash buyers. This means that while the index is the most appropriate available source on property price changes, it

1 The CSO uses three-month moving averages for the RPPI series in order to smooth out short-term volatility in the series and highlight longer-term trends. 
does not capture all transactions. ${ }^{2}$ As a result, its representativeness of the whole residential property market may vary over time, in line with the total proportion of transactions made up of mortgages. The RPPI is not seasonally adjusted. There is also a lag, typically of one to three months, between when the sale closes on a property and when the mortgage is drawn down, which affects the real-time nature of the index. Despite these imperfections, previous analysis has shown that property price changes derived from other sources correlate closely with the RPPI (Daft.ie, 2012).

By definition, as each index and sub-index represents an average change, the RPPI does not show price changes for each individual property. The index masks the diversity of price paths of properties with particular characteristics such as number of bedrooms, floor area, etc. However, differences in these characteristics are controlled for by the CSO in constructing the index. Similarly, not revealed in the RPPI sub-indices are the differing price paths across the different regions, i.e. within Dublin and across counties.

Over the period from May 2013 to May 2015, property prices increased nationally by 26 per cent. This overall increase masks the variation in increases across regions, with properties in Dublin increasing by approximately 41 per cent, while properties outside of Dublin increased by 14 per cent. Similarly there were substantial differences between the house and apartment price indices on a national basis. Figure 1 shows price developments since May 2013 for each of the sub-indices of the RPPI, with each index rebased to 100 in May 2013.

\section{Residential Property Price Register}

The Property Services Regulatory Authority (PSRA) publishes a Residential Property Price Register ('the property register'). The property register includes information on date of sale, price and address for all residential properties transacted in Ireland since 1 January 2010, as declared to the Revenue Commissioners for stamp duty purposes. ${ }^{3}$ In addition, it identifies whether the price shown

\footnotetext{
2 The number of mortgages drawn down (data from Banking \& Payments Federation Ireland) appears to have been relatively steady at just under 50 per cent of the total number of residential properties transacted (data from the Residential Property Price Register) over the period.

3 According to the PSRA, the data in the register are compiled from data which are filed, for stamp duty purposes, with the Revenue Commissioners. The data are primarily filed electronically by persons conveyancing the property on behalf of the purchaser, and errors may occur when the data are being filed.
} 


\section{Figure 1: CSO RPPI developments, May 2013 to May 2015 (May $2013=100)$}

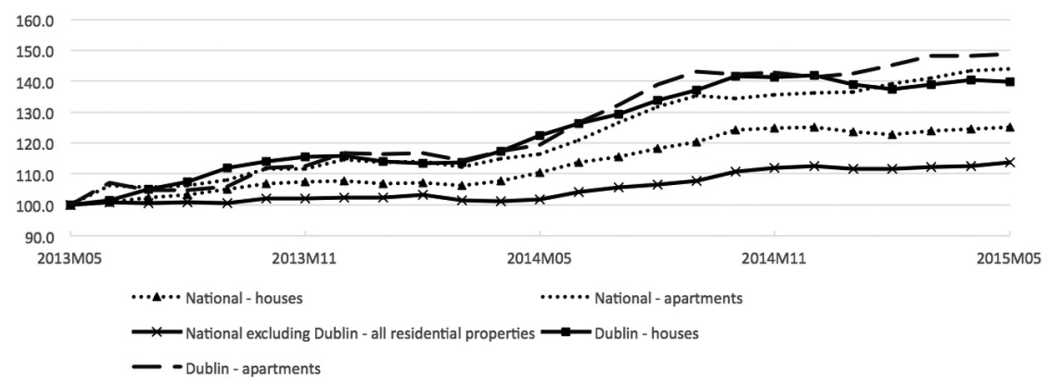

Source: CSO.

Note: The overall national index is not displayed as it broadly mirrored the national houses index given the high weighting of houses in the index.

represents the full market price and whether the property was a second-hand or new dwelling. In the case of the latter, prices are recorded on a VAT-exclusive basis.

For illustrative purposes Figure 2 reports national price developments over the period as indicated by the median price in the property register, alongside the CSO's RPPI reading. Though they follow broadly similar trends, it can be seen that the median price from the property register is more volatile than the hedonic, regressionbased RPPI.

Over the period 2010-14 more than 136,000 transactions were recorded in the property register. ${ }^{4}$ This compares with the overall stock of residential properties of 2 million according to the 2011 Census and of 1.85 million according to property tax filings made to the Revenue Commissioners. The total number of property transactions on the register over this period therefore represents as much as 7 per cent of the total stock. ${ }^{5}$ The breakdown of properties recorded in the property register on an annual basis from 2010 to 2014 is presented in Table 1.

\footnotetext{
${ }^{4}$ The construction and cleaning of the data set took place in Spring 2015.

5 This ignores situations where particular properties are transacted multiple times.
} 
Figure 2: Property price developments, CSO RPPI \& Residential Property Price Register median, May 2013 to May 2015

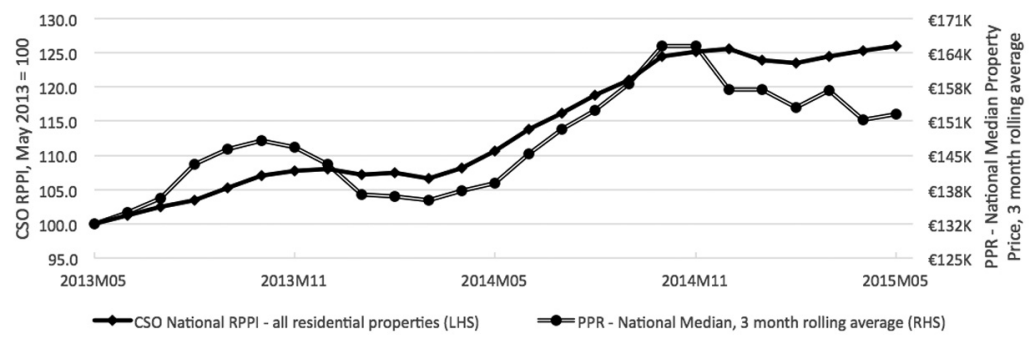

Table 1: Observations from PSRA Residential Property Price Register, 2010-14

\begin{tabular}{lc}
\hline Year & Number of observations \\
\hline 2010 & 20,900 \\
2011 & 18,200 \\
2012 & 25,100 \\
2013 & 29,700 \\
2014 & 42,100 \\
Total & 136,000 \\
\hline
\end{tabular}

\section{Estimating a distribution of market values in May 2013}

As described later in the paper, the Revenue Commissioners hold considerable data on the numbers of properties in each property tax valuation band in May 2013, both nationally and at a county level. The data are based on property owners' own valuations at that time. However, as property owners were not asked for an actual value estimate, but rather which valuation band the property fell within at that time, ${ }^{6}$ the usefulness of this data source in modelling the impact of recent property price changes is limited. While a single sample point from a band could be rolled forward by reference to recent price growth - for instance, the mid-point of a band - the wide range of

\footnotetext{
6 The LPT is based on market value bands, with twenty valuation bands. The first band covers all properties worth up to $€ 100,000$. The next eighteen bands then increase in multiples of $€ 50,000$. If a property is valued at $€ 1$ million or lower - i.e. if it is in the first nineteen bands - the tax is based on the midpoint of the relevant band. Properties in Band 20 are those properties valued over $€ 1$ million. The basic LPT rate was set at 0.18 per cent for properties valued under $€ 1$ million and 0.25 per cent on the amount of the value over $€ 1$ million.
} 
variation of actual prices within each band would result in very large estimation errors. Instead we use an alternative approach based on a sample of the overall stock of property values based on the property register.

For the purposes of analysing the property register data, it was necessary to undertake some cleaning and adjustments to the data. While this approach required an element of judgement, it was necessary in order to draw reasonable analytical inferences from the data:

- First, some 6,500 transactions that were marked as being conducted at a price not equivalent to 'full market value' were removed.

- Second, an exercise was undertaken to remove errors, which included incorrect prices, double or multiple entries of the same properties, and single entries that represented multiple transactions (e.g. if an apartment complex was transacted).

- Third, a further 300 entries were removed where the value was below $€ 10,000$, a threshold below which the transaction may not relate to a finished property.

- This leaves a total sample size, after data cleaning, of 128,700 properties (see Table 2).

Table 2: Steps in data-cleaning exercise

\begin{tabular}{lc}
\hline & Number of observations \\
\hline Total observations & 136,000 \\
Remove properties marked 'not full value' & 129,600 \\
Remove errors and multiples & 129,000 \\
Remove all properties less than $€ 10,000$ & 128,700 \\
\hline
\end{tabular}

In addition to removing some observations to enable a more accurate and representative sample, it was also necessary to add back the VAT onto the 'VAT-exclusive' price at which new dwellings in the register were recorded. This affected some 19,000 entries in the register.

Having cleaned the property register data, all remaining observations from 2010-14 were rebased to May 2013 prices using the CSO's RPPI. In order to capture some degree of the variation in property prices across the country, the sample was split into three regions and an applicable index from the RPPI was applied as follows: 
i. Dublin houses and apartments were rebased using the Dublin house and apartment price indices, respectively.

ii. Houses and apartments in the Dublin commuter counties of Kildare, Meath and Wicklow, as well as Cork City and Galway City, were rebased according to the national house and apartment price indices, respectively.

iii. Properties in all other areas were rebased using the "national excluding Dublin' index.

The justification for this approach is the variation in property price developments across the country since the May 2013 Revenue LPT valuation date. As illustrated earlier, Dublin property prices have increased faster than other regions while price changes for the second grouping have been notably different to those in Dublin and in the remaining counties. ${ }^{7}$ As indicated by Table 3, the property register contains a large number of observations for each of the geographical groups.

Table 3: Groupings by CSO RPPI sub-index used for rebasing (number of Residential Property Price Register observations)

\begin{tabular}{lcc}
\hline & Apartments & Houses \\
\hline Group 1: Dublin & Dublin: 4,700 & Dublin: 20,700 \\
$\begin{array}{l}\text { Group 2: Commuter } \\
\text { counties, and Cork }\end{array}$ & & \\
and Galway cities & National: 700 & National: 38,600 \\
$\begin{array}{l}\text { Group 3: All further } \\
\text { counties }\end{array}$ & $\begin{array}{c}\text { National excluding Dublin - all residential } \\
\text { properties: 64,000 }\end{array}$ \\
\hline
\end{tabular}

It should be noted that the CSO 'national excluding Dublin' index, which is applied to Group 3, includes the geographical areas in Group 2 , and similarly Dublin is contained within the CSO national index that is applied to Group 2. Given the changes in the RPPI, this could potentially introduce upward bias for Group 3 in particular.

After the property prices in the property register have been rebased to May 2013 prices, it is possible to assign the observations in our

\footnotetext{
7 The increase in the RPPI from May 2013 to May 2015 was 41 per cent for Dublin, 26 per cent nationally, and 14 per cent nationally excluding Dublin. For comparison, from Q2 2013 to Q2 2015 the Daft.ie asking price index increased by 39 per cent in Dublin, 22 per cent in the commuter counties and in Cork and Galway cities, and 5 per cent in all further counties.
} 
rebased sample of 128,700 properties to the property tax valuation bands. The distribution of values across bands in the rebased sample can then be compared with the distribution according to the Revenue data. These distributions are presented in Figure 3.

\section{Figure 3: Comparison of distributions of rebased property register and Revenue filings by valuation band, national, 2013}

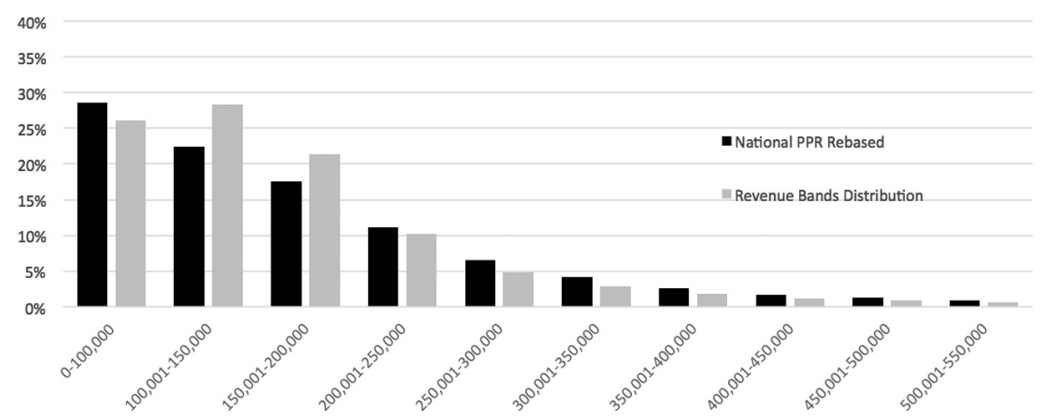

Sources: Property Services Regulatory Authority, Revenue, CSO, Department of Finance Analysis.

As can be seen, the total distribution in the rebased property register sample is broadly similar to the distribution based on filings made to the Revenue Commissioners. There is a slightly higher incidence of properties in Bands 2 and 3 in the Revenue distribution, with a compensating higher incidence of properties in other valuation bands in the rebased property register sample. Factors influencing these differential patterns include the impact of local authority owned housing (discussed below), as well as a relatively higher frequency with which different-value properties are transacted (i.e. it is possible that buyers and sellers of higher-value properties were less constrained in conducting transactions over the period considered).

For Dublin the rebased property register distribution has a significantly lower incidence of properties in the first valuation band relative to the Revenue distribution. Thereafter the distributions are broadly similar. The deviation in the first valuation band may be explained by the higher incidence of local authority owned housing in Dublin, which accounts for some 51,000, or 35 per cent, of the total stock of 149,000 local authority owned units in the country.

Local authority owned units are very unlikely to have transacted over the period 2010-14 and, as such, will not be represented on the 
property register. Furthermore all local authority owned properties were assigned to the first valuation band until 2016 under Section 17 (6) of the Finance (Local Property Tax) Act, 2012, thus creating a temporary disconnect between a market value distribution of property values and the distribution of filings made to Revenue.

When these factors - the impact of local authority owned housing, and the higher frequency with which different-valued properties are transacted - are taken into account, it is evident that the rebased property register is broadly representative of the Revenue filings in May 2013 for both the national and Dublin distributions.

The actual variation of values within the Revenue valuation band filings is not known. This limits the usefulness of the Revenue distribution in modelling the impact of recent price changes. However, on the basis that the rebased property price register data appear to be broadly representative of the actual Revenue filings in terms of variation across bands, it appears reasonable to use variation within bands from the rebased property register data as a proxy for variation within the Revenue bands. In other words, the estimated distribution of property values within a given valuation band in the rebased sample will be used as a proxy for the actual distribution of values within the same band in the Revenue distribution. ${ }^{8}$

The next section uses the variation within bands in the rebased sample to roll forward the full population of property values from the Revenue filings to take account of recent price changes. We then use these estimates to analyse the impact that price changes could have on taxpayer liabilities if a revaluation for LPT purposes were to take place using the existing band and rate structure.

\section{Implications of price developments for taxpayer liabilities}

In the previous section we generated a distribution of estimated market values in May 2013 prices based on a sample of 128,700 properties from the property register. When assigned to valuation bands, the sample was shown to be broadly representative of the valuation bands distribution based on filings made to the Revenue Commissioners.

${ }^{8}$ An analysis of the Residential Property Price Register indicates that properties are uniformly distributed within bands such that it would be expected that 2 per cent of properties in each $€ 50 \mathrm{k}$ band would be expected to lie within each $€ 1 \mathrm{k}$ sub-interval. 
This section applies price changes since the May 2013 valuation to the sample from the property register to estimate the impact of price changes on taxpayer liabilities. This involves three steps:

i. First, the values of all of the properties in the sample are rolled forward to a May 2015 price basis to account for price trends since the first property tax valuation (May 2013).

ii. Next, as an analytical tool, a transition matrix is constructed that maps the movement in property tax bands for each property in our sample between May 2013 and May 2015.

iii. Finally, the variation in prices in the sample is used to construct a transition matrix for the overall stock of properties that is consistent with the Revenue distribution, variants of which are presented at the end of the section.

\section{Methodology}

Step 1: Rebase to May 2015

The values from the property register are rolled forward to May 2015 using the same approach to indexation as used in constructing an estimate of May 2013 values. The results are presented in Figure 4.

Figure 4: Estimates of property valuations from the property register distributed by valuation band, May 2013 and May 2015

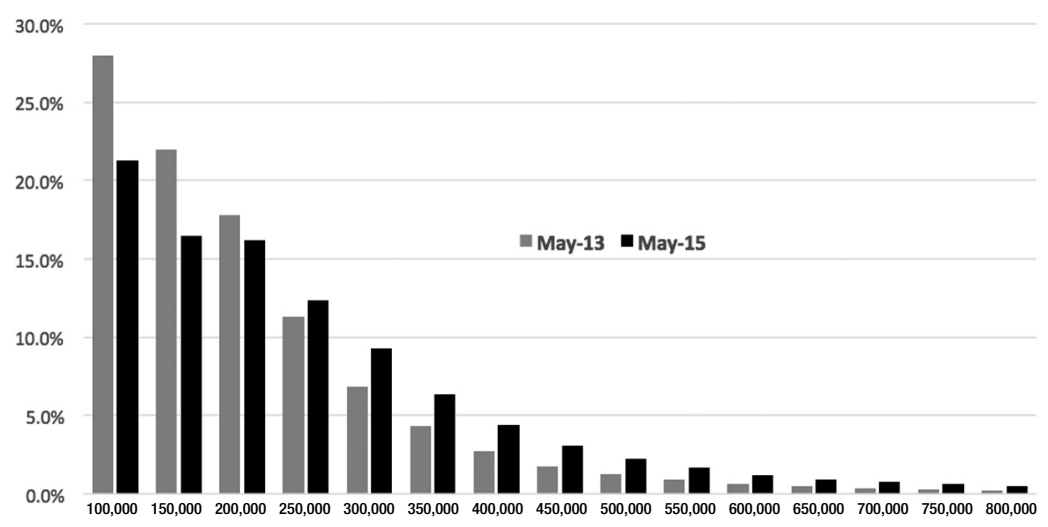

Sources: Property Price Register, CSO, Department of Finance analysis.

As can be seen in Figure 4 there is a higher incidence of properties estimated in all but the first three bands in May 2015 relative to May 
2013. In other words, as property values have increased, the distribution by valuation bands has shifted to the right. This shift in valuation bands is indicative of an increase in property tax liabilities as a result of property price increases. To identify the extent of estimated increases and how they are distributed relative to May 2013 valuation bands, and by geographical area, we construct a transition matrix.

\section{Step 2: Transition matrix for sample}

A transition matrix is a useful analytical tool that maps the movements in property prices across valuation bands between two time periods. The rows in the transition matrices in Annex 1 represent the property valuation bands in May 2013 while the columns indicate the bands in May 2015. Thus, the entries across a row in the transition matrix show the 'transitions' of properties in a given valuation band in 2013 to valuation bands in May 2015 as a result of changes in property values over the period.

For instance, Row 1 of a transition matrix will report the movements in properties that were valued in Band 1 in May 2013 (i.e. properties valued less than $€ 100,000)$ by allocating properties to various valuation bands based on their modelled valuation changes over the period. Properties are assumed to grow in line with average price changes in their respective region. ${ }^{9}$ Rows 2 to 20 of the transition matrix will report similar results for properties that were valued in Bands 2 to 20 in May 2013.

A transition matrix is first constructed for the property register sample. The next step involves applying population weights from the Revenue distribution to convert from a matrix based on the sample to a transition matrix for the full population of residential properties.

\section{Step 3: Transition matrix for population}

In constructing the transition matrix for the overall stock of properties, the variation in prices in the sample is used to construct a transition matrix for the overall stock of properties that is consistent with the Revenue distribution. Separate estimates are made for Dublin and the rest of the country, referred to as 'national outside Dublin', which are then summed to create a national transition matrix. Variants of these 'population' transition matrices are presented at the end of the section.

\footnotetext{
${ }^{9}$ An implication of this assumption is that no property fell in value over the period May
} 2013 to May 2015. 
The tables in Annex 1 present the results of the transition matrix analysis. Nine tables are presented, three for the national distribution, three for Dublin and three for 'national outside Dublin', which show:

- first, the total number of properties that are estimated to have 'transitioned'; 10

- second, the share of properties that have transitioned as a percentage of the total stock; ${ }^{11}$ and

- third, the share of transitions as a percentage of the stock in each Revenue valuation band in 2013. ${ }^{12}$

The results indicate large variation in possible changes to tax liabilities by geographical area, suggesting large variation in tax liabilities across the geographical and value distributions.

\section{National transitions}

The national transition matrices (Annex Tables 1-3) indicate that:

- 48 per cent of properties remained in their original band; ${ }^{13}$

- 35 per cent of properties moved up by one band;

- 10 per cent of properties moved up by two bands; and

- the remainder moved up by between three and six valuation bands.

A more detailed inspection of band movements from May 2013 shows that for properties that were valued in the first five bands in 2013 (i.e. properties with 2013 market values below $€ 300,000$ and which accounted for 92 per cent of the overall stock), the maximum number of band movements is estimated at three. ${ }^{14}$ These are modelled to have occurred for properties that were in Bands 4 and 5 in 2013 (i.e.

10 Annex Tables 1, 4 and 7 for national, Dublin and national outside Dublin, respectively.

11 Annex Tables 2, 5 and 8 for national, Dublin and national outside Dublin, respectively.

12 Annex Tables 3, 6 and 9 for national, Dublin and national outside Dublin, respectively.

13 This is calculated as the sum of the diagonal from the first cell (Band 1 May 2013, Band 1 May 2015) to the last cell (Band 20 May 2013, Band 20 May 2015) in Annex Table 3. The figures in the transition tables assume that social housing properties (which are deemed to be in Band 1 in May 2013) remain in Band 1 on revaluation.

14 It should be noted that price increases applied in this analysis are average changes. Thus, actual properties will be more dispersed in terms of band changes relative to the results presented herein, and will include band movements of more than three bands. 
properties valued between $€ 200,000$ and $€ 300,000$ ). However, as shown in Table 4, which is taken from Annex Table 3, the majority of properties in each of these 2013 valuation bands are estimated to have moved up by two bands or less.

The remaining 5 per cent of properties nationally are those that had a market value greater than $€ 350,000$ in 2013. Some properties within this group (those that were valued between $€ 550,000$ and $€ 750,000$ in 2013) will have jumped by as much as six bands. However, this group of properties only represents approximately 1 per cent of the overall stock.

\section{Dublin}

In Dublin the transition matrices (Annex Tables 4-6) indicate that between May 2013 and May 2015:

- 14 per cent of properties remained in their original band; $; 5$

- 31 per cent of properties moved up to the next band;

- 33 per cent of properties moved up by two bands;

- 13 per cent of properties moved up by three bands; and

- 9 per cent moved up by between four and six valuation bands.

In Dublin the largest estimated movements in bands over the period are for properties that were valued in Bands 6 to 14 in 2013; in other words, properties valued between $€ 300,000$ and $€ 750,000$ at that time. Some properties in this group are estimated to have moved up by between four and six valuation bands. Sizeable jumps are found for the majority of properties in each of these bands. For instance:

- In Band 7 ( $€ 350,000$ to $€ 400,000) 83$ per cent of properties are estimated to have moved up by three bands or more;

- In Band 8 (€400,000 to $€ 450,000) 100$ per cent of properties are estimated to have moved up by three bands or more; and

- In Band 12 (€600,000 to $€ 650,000) 84$ per cent of properties are estimated to have moved up by five bands or more.

It is unsurprising that some properties in Dublin are estimated to have seen greater movement in valuation bands compared with the overall national transitions. This is a function of both the higher incidence of

15 This is calculated as the sum of the diagonal from the first cell (Band 1 May 2013, Band 1 May 2015) to the last cell (Band 20 May 2013, Band 20 May 2015) in Annex Table 6. 


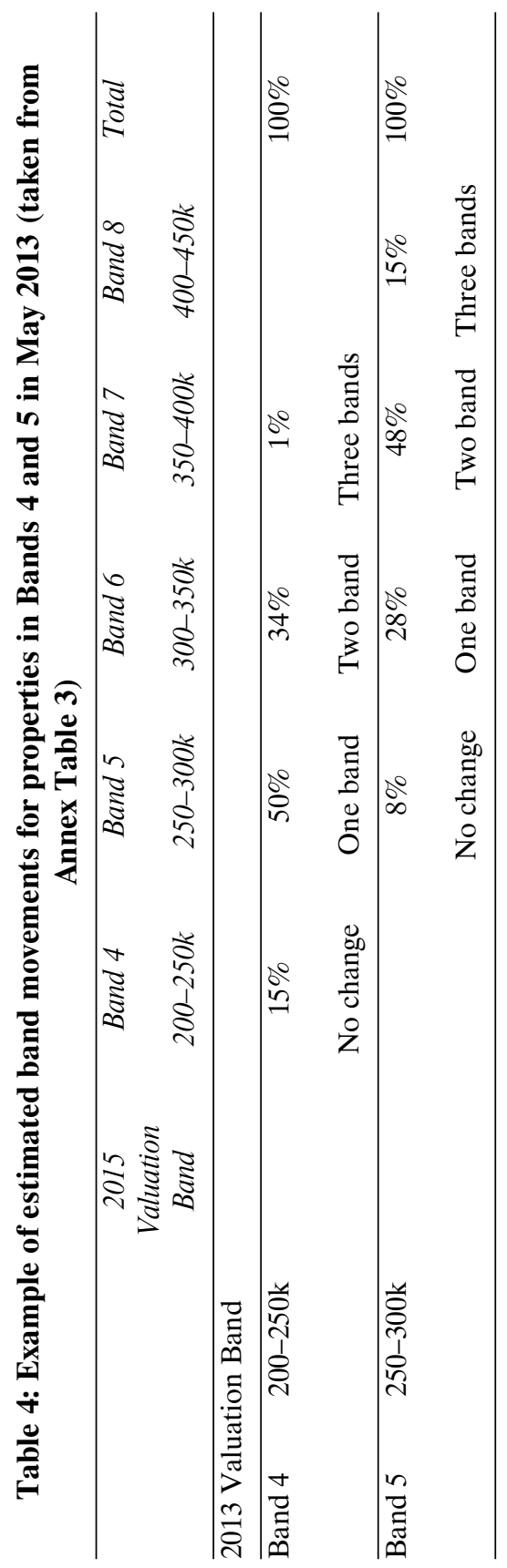


higher-value properties in Dublin and the higher average rate of property price increase in the region. The implication of the former is that given an equivalent proportionate increase in property prices, higher-valued properties will move up a greater number of valuation bands than lower-value properties.

On the other hand, large movements through valuation bands for higher-value properties result in similar proportional changes in the LPT liability as occurs for smaller band movements for relatively lower-value properties. For instance, the changes in liability for movements of five to six bands for properties originating in Bands 11, 12 and 13 are in the range of 37 per cent to 52 per cent, which is similar to the 35 per cent to 53 per cent change in liability for properties originating in Bands 7 and 8 that moved up by three to four bands.

It should also be noted that properties in Bands 7 to 14 in 2013 values accounted for 15 per cent of the stock of properties in the Dublin area. Nationally only 5 per cent of properties were in these valuation bands in 2013, the majority of which were in Dublin. As noted above, over three-quarters of properties in Dublin are found to have moved up by no more than two valuation bands, with 30 per cent of all properties modelled to have moved up by just one band.

\section{National outside Dublin}

The 'national outside Dublin' transition matrices (Annex Tables 7-9) indicate that:

- 61 per cent of properties remained in their original band; $; 6$

- 37 per cent of properties moved up by one band; and

- the remaining 2 per cent of properties moved up by between two and five bands.

The combination of lower property values - 95 per cent of properties were estimated to be in the first four bands as of May 2013 - and more moderate property price increases leads to estimates that the vast bulk of properties either experience no band movement or a single band jump. Roughly 0.25 per cent of properties are found to have moved up by three bands or more.

16 This is calculated as the sum of the diagonal from the first cell (Band 1 May 2013, Band 1 May 2015) to the last cell (Band 20 May 2013, Band 20 May 2015) in Annex Table 9. 


\section{Yield estimates}

Using the distribution of property values estimated, and set out in Annex 1, it is possible to generate a projection of the revenue yield which would result if the current property tax regime (i.e. the current valuation band and rate structure) was maintained and applied to the estimated May 2015 property values.

In this section we describe a method for generating a yield estimate associated with the estimated updated property values. This involves applying the current property tax regime to the May 2015 estimated property value distribution.

\section{Yield estimation method}

The method for calculating transition matrices involves using variation within bands from the property register as a proxy for variation within bands in the Revenue distribution in 2013, and using this proxy to roll forward the Revenue bands into a 2015 price basis. We therefore start by constructing a 2013 yield purely on the basis of the Revenue distribution - i.e. assuming no deferrals, exemptions or non-payments - and comparing this with actual collections that year. This acts as a benchmark to test the accuracy of estimate projections and indicates the appropriateness of the yield estimation methodology used. The differential is then incorporated when estimating a yield based on price changes up to May 2015.

Next the estimated 2015 property price distribution from the national transition matrix is used to estimate a yield based on May 2015 values. This method involves multiplying the number of properties estimated to be in each band in May 2015 by the applicable property tax due for that band.

The estimated yield for May 2015 is then adjusted to account for a range of factors, including exemptions, deferrals, local authority owned housing and non-compliance. The impact of the local adjustment factor rate changes adopted by some local authorities in 2015 is also considered.

\section{Step 1: Calibration}

The transition matrices provide the number of properties in each valuation band as of May 2013 (as well as 2015). By multiplying the number of properties in each band by the property tax liability for that band in 2013, an estimated yield can be calculated.

For example, for the first band, the property tax due of $€ 90$ (0.18 per cent times the midpoint of the $0-100 \mathrm{k}$ band) is multiplied by the 
572,500 properties declared to be in this band in May 2013 for an estimated revenue yield from Band 1 properties of $€ 52$ million. The same process is then applied to each subsequent band and the total summed to estimate the full LPT liability. This yields an initial, indicative LPT liability estimate based on May 2013 values of $€ 520$ million.

The estimated figure of $€ 520$ million is in excess of the actual liability of approximately $€ 500$ million for 2014 indicated by the Revenue Commissioners ( $€ 489$ million LPT declared, including deferrals, and $€ 12$ million LPT exempt) in the Local Property Tax (LPT) Statistics (Revenue, 2015), representing a 5 per cent overestimate. Possible explanations for the difference include work items currently being processed, the measurement of valuations for exempt properties, and late or partial payment for some properties (for mandatory deduction-at-source cases in particular, payment for 2014 may be ongoing).

It should be noted that these actual and estimated figures are before deferrals and exemptions are taken into account, and also do not adjust for any local adjustment factor applied by local authorities.

\section{Step 2: Yield estimate}

Rolling forward to an estimate based on May 2015 property prices, the same process can be used with some alterations. An adjustment is made to account for local authority housing, which was assigned a deemed valuation in the first band. To estimate the LPT liability for May 2015 property values, these local authority properties (almost 150,000 properties) are assumed to remain assigned to Band 1 .

The 2015 property price distribution from the national transition matrix, as presented in Annex 1, is used to estimate a yield at May 2015. This method involves multiplying the number of properties estimated in each band at May 2015 by the applicable property tax due for that band. After accounting for local authority housing, this approach leads to an estimated indicative LPT liability of €670 million based on May 2015 property values. This compares to the initial indicative $€ 520$ million liability estimate for May 2013 noted above.

When adjusted to take account of the 2013 calibration process, incorporating the expectation of a small (i.e. 4.4 per cent) overestimate, the point estimate for LPT liability in May 2015 prices is reduced to approximately $€ 640$ million. This represents an increase of $€ 140$ million ( 28 per cent) over the actual $€ 500$ million liability for 2014 based on May 2013 valuations, and provides an illustration of the 
potential tax revenue impact of the recent price developments in the property market.

Further adjustment for exemptions and deferrals, assuming their proportions remain consistent at 2 per cent and 1 per cent of properties, respectively, would suggest that the point estimate for the indicative LPT collection would be closer to $€ 620$ million. This compares to the $€ 480$ million LPT actually collected for 2014, again an increase of $€ 140$ million.

The revenue yield estimate does not account for the local adjustment factor (LAF) of up to 15 per cent, which a local authority has been allowed to apply to the basic rate of property tax within its own area from 2015 onwards. At the time of the Thornhill review the Revenue Commissioners estimated that the LAFs set by local authorities for 2015 would have the impact of reducing LPT collected by $€ 45$ million, from $€ 480$ million to $€ 435$ million. If each local authority holds their LAF constant and the impact of the LAF were to grow in line with the estimated increase in LPT collection in Dublin and outside of Dublin, an indicative estimate of the possible impact of the LAF can be made. Based on these two assumptions, the LAF impact after a May 2015 revaluation would be of the order of $€ 60$ million, reducing the estimated indicative LPT liability from $€ 620$ million to $€ 560$ million. Thus, after accounting for the LAF, LPT collection could be expected to increase by $€ 125$ million, from $€ 435$ million based on May 2013 property valuations to $€ 560$ million based on May 2015 valuations (see Table 5).

\section{Table 5: Estimates of LPT liability based on May 2015 valuations compared to 2013 values}

\begin{tabular}{lcc}
\hline $\begin{array}{l}\text { Estimated tax } \\
\text { revenue impact }\end{array}$ & $\begin{array}{c}\text { Actual liability } \\
\text { (based on } \\
\text { May 2013 valuations) } \\
(€ m)\end{array}$ & $\begin{array}{c}\text { Indicative liability } \\
\text { (based on roll forward } \\
\text { to May 2015 values) } \\
(€ m)\end{array}$ \\
\hline $\begin{array}{l}\text { LPT liability for 2014 } \\
\text { LPT liability for 2014 } \\
\text { (excluding exemptions } \\
\text { and deferrals) }\end{array}$ & 500 & 640 \\
$\begin{array}{l}\text { LPT liability for 2015 } \\
\text { (following local adjustment } \\
\text { factor, and excluding } \\
\text { exemptions and deferrals) }\end{array}$ & 480 & 620 \\
\hline
\end{tabular}




\section{Estimated changes in LPT liability by valuation band}

The analysis suggests that estimated total LPT liability from the first three bands would decrease, as the number of properties valued between $€ 0$ and $€ 200,000$ is estimated to have fallen between May 2013 and May 2015. However, an increased liability is indicated for all other bands.

The largest increase in property tax liability is estimated for those properties valued over $€ 1$ million (i.e. Band 20). The yield from properties in Band 20 is estimated to have increased by $€ 30$ million (650 per cent) between May 2013 and May 2015. Due to the high liability applicable to these high-value properties, a small absolute increase in the number of properties liable results in a large increase in total tax liability. By comparison, the next highest liability increases of $€ 22-25$ million, for Bands 4, 5 and 6, arise from the large volume of properties in those bands.

\section{Conclusions and considerations regarding approach used}

While there is no single source of data on actual stock property values at the time of the first valuation for LPT purposes in May 2013, we use a range of sources to estimate a representative sample of market values at that time. We take account of changes in property prices by rolling forward these values based on price developments since the original valuation period. The implications of these price changes for taxpayer liabilities can then be estimated. On the basis of this approach, we estimate that if a revaluation were to take place based on price changes up to May 2015:

- 48 per cent of properties would remain in their original valuation band;

- 35 per cent of properties would move up by one valuation band;

- 10 per cent of properties would move up by two bands; and

- the remainder would move up by between three and six valuation bands.

This indicates that if a revaluation were to have occurred following the Thornhill review, there would have been significant increases in tax liabilities for some taxpayers, with properties in the higher valuation bands in May 2013 experiencing the largest number of band movements. The analysis also indicates a wide degree of regional 
variation in band changes, with the largest movements in bands mainly occurring in the Dublin area.

A conservative element built into the approach used is the nonincorporation of the currently exempt properties which may become liable in 2017. At the time of the Thornhill review it was estimated that 14,000 properties were exempt on the grounds that they fell within the first-time-buyer exemption in 2013 or that they were purchased for the first time after 2013.17

The approach also relies on a conservative assumption that the average LPT liability per property in Band 20 (i.e. properties valued over $€ 1$ million) will remain constant. Unlike all other bands, properties in Band 20 do not have a fixed LPT liability (i.e. a band midpoint times a rate). Instead the first $€ 1$ million is charged at the standard rate (e.g. $€ 1$ million $\times 0.0018$ per cent $=€ 1,800$ ) and an $a d$ valorem charge is applied to the increment above $€ 1$ million. In the absence of point estimates for properties valued above $€ 1$ million it is assumed that the total LPT liability for this band in both periods equals the current average payment times the estimated volume of properties in Band 20 in May 2015.

As outlined previously, there may be some upward bias in the estimated yield arising from the use of the various CSO indices for the different regions. This may lead to an overestimate in terms of the estimated yield. Though it would seem unlikely, an increase in exemptions would depress the liability estimate. Any increases in the rate of deferrals would increase the gap between liability and LPT collected in a given year.

While these various factors will affect the estimates produced, their overall significance will be outweighed by any major price developments subsequent to May 2015. In this light, to reflect further changes in residential property prices, it may be appropriate to repeat the analysis when the rate of price change has stabilised for a period of time. Nonetheless, the main takeaway from this paper - that revaluation will have regional differences - would almost definitely still apply in any revised estimates.

If the data and resources were available, further enhancements could potentially include greater disaggregation based on smaller geographical areas (e.g. counties) and incorporate the different price

17 As part of the Finance (Local Property Tax) (Amendment) (No. 2) Bill, 2015, the exemption of these properties was extended to 2019, in line with the new legislated revaluation date of 1 November 2019. 
paths followed by different property types (e.g. number of bedrooms and property type).

While the use of transition matrices for estimating potential tax liabilities may be a novel policy tool, there would seem to be logical extensions to this type of analysis. For example, it would appear that future research and estimations of changes in policy rates could be undertaken in the areas of stamp duty and capital gains tax.

\section{Annex 1: Transition matrices}

A transition matrix is a useful analytical tool that maps the movements in property prices across valuation bands between two time periods. In the transition matrices below, the rows represent the property valuation bands in May 2013 while the columns indicate the bands in May 2015. Thus, the entries across a row in the transition matrix show the 'transitions' of properties from a given valuation band in 2013 to valuation bands in May 2015 as a result of changes in property values over the period.

For instance, take Annex Table 1. Row 1 of the transition matrix will report the movements in properties that were valued in Band 1 in May 2013 (i.e. 572,500 properties valued at less than $€ 100,000$ ). Of these, 479,100 are estimated to remain within Band 1, while 93,400 are estimated to have 'transitioned' to Band 2. Rows 2 to 20 of the transition matrix will report similar results for properties that were valued in Bands 2 to 20 in May 2013.

Annex Table 2 reports these transitions as a proportion of the housing stock. Row 1 reports that 31 per cent of the housing stock was valued in Band 1 in May 2013. This is calculated from the figures in Annex Table 1 as 572,500 divided by the total stock of 1,847,500. As of May 2015 valuations, this 31 per cent of the housing stock is subcategorised into 25.9 per cent remaining in Band 1 and 5.1 per cent moving to Band 2. Rows 2 to 20 of the transition matrix will report similar results for properties that were valued in Bands 2 to 20 in May 2013.

Annex Table 3 considers the transitions within each May 2013 band as of May 2015. Row 1 indicates that 84 per cent of properties in Band 1 in May 2013 are estimated to remain in Band 1 based on May 2015 valuations. This is calculated from Annex Table 1, Row 1 as 479,100 divided by the total 572,500 initially in this band. The remaining 16 per cent of properties originally in Band 1 are estimated to move to Band 2 . Rows 2 to 20 of the transition matrix will report similar results for properties that were valued in Bands 2 to 20 in May 2013. 


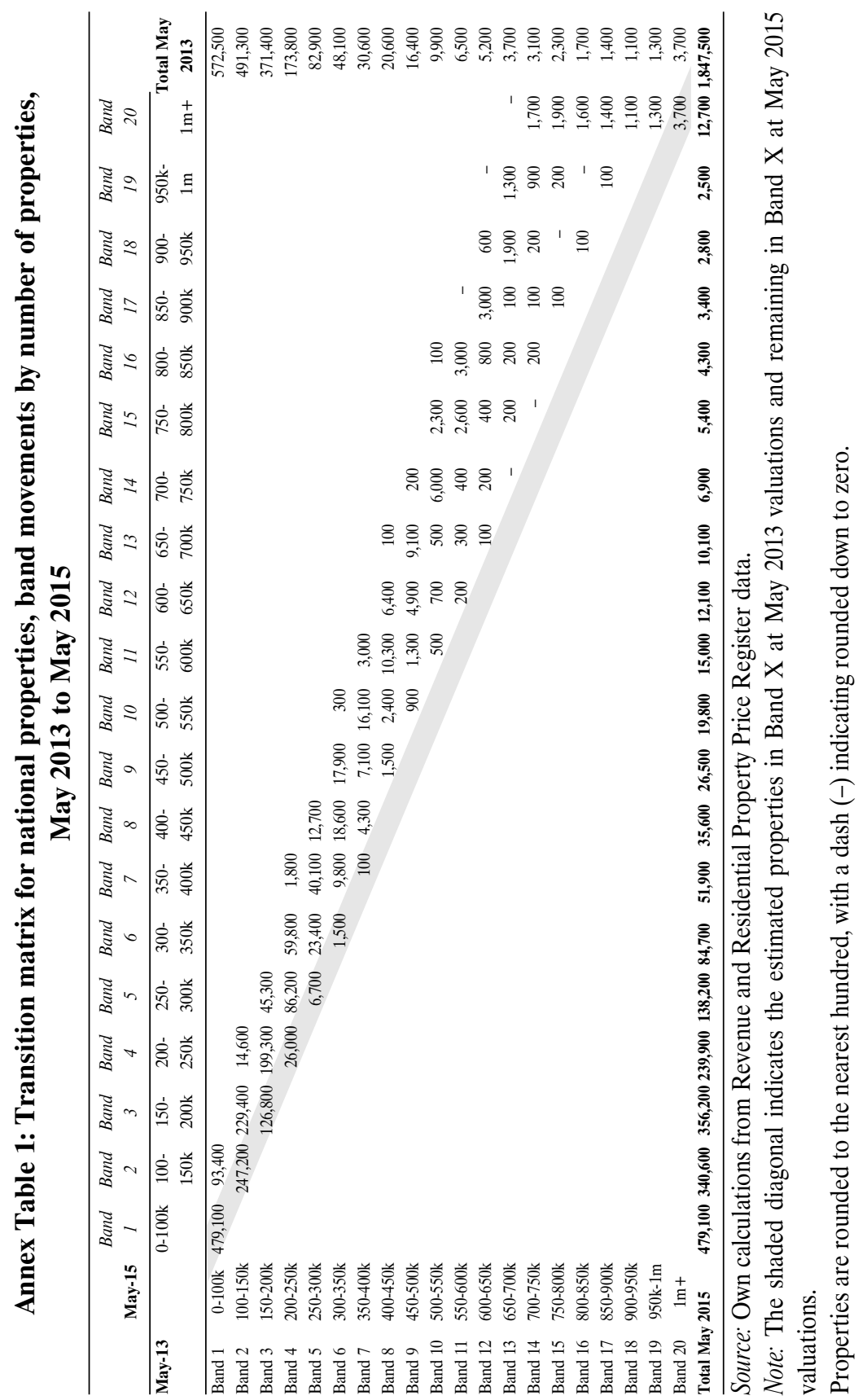




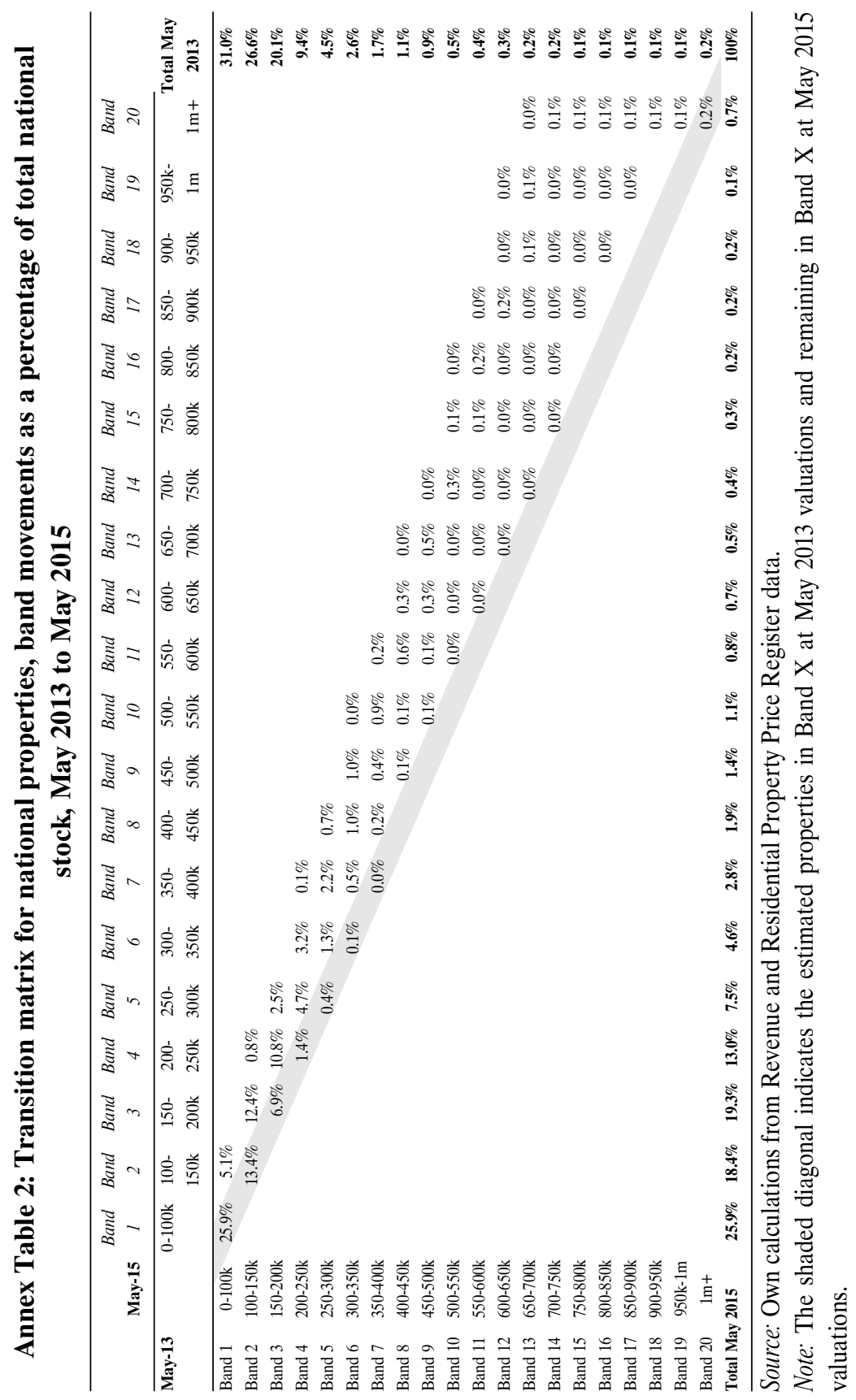




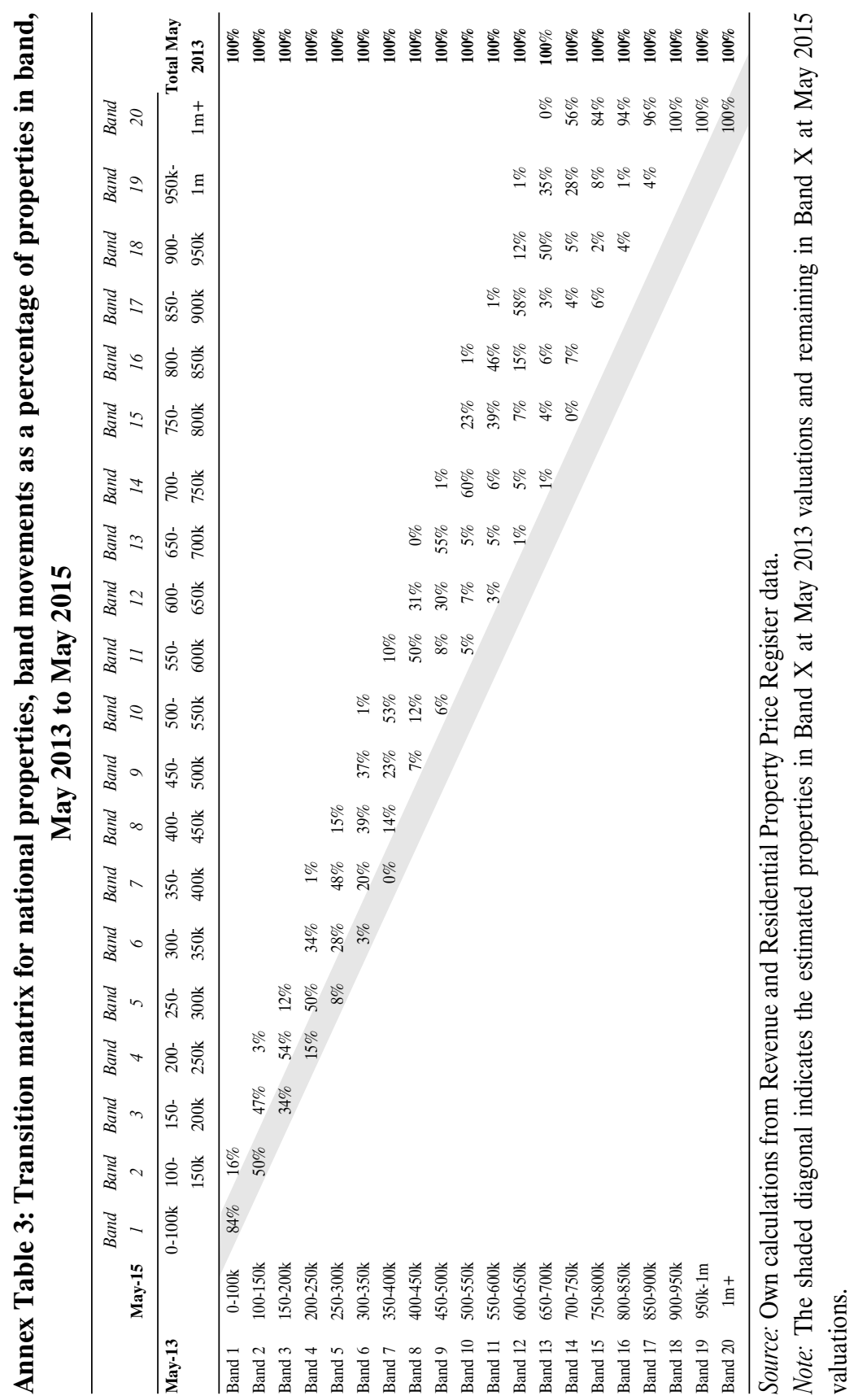




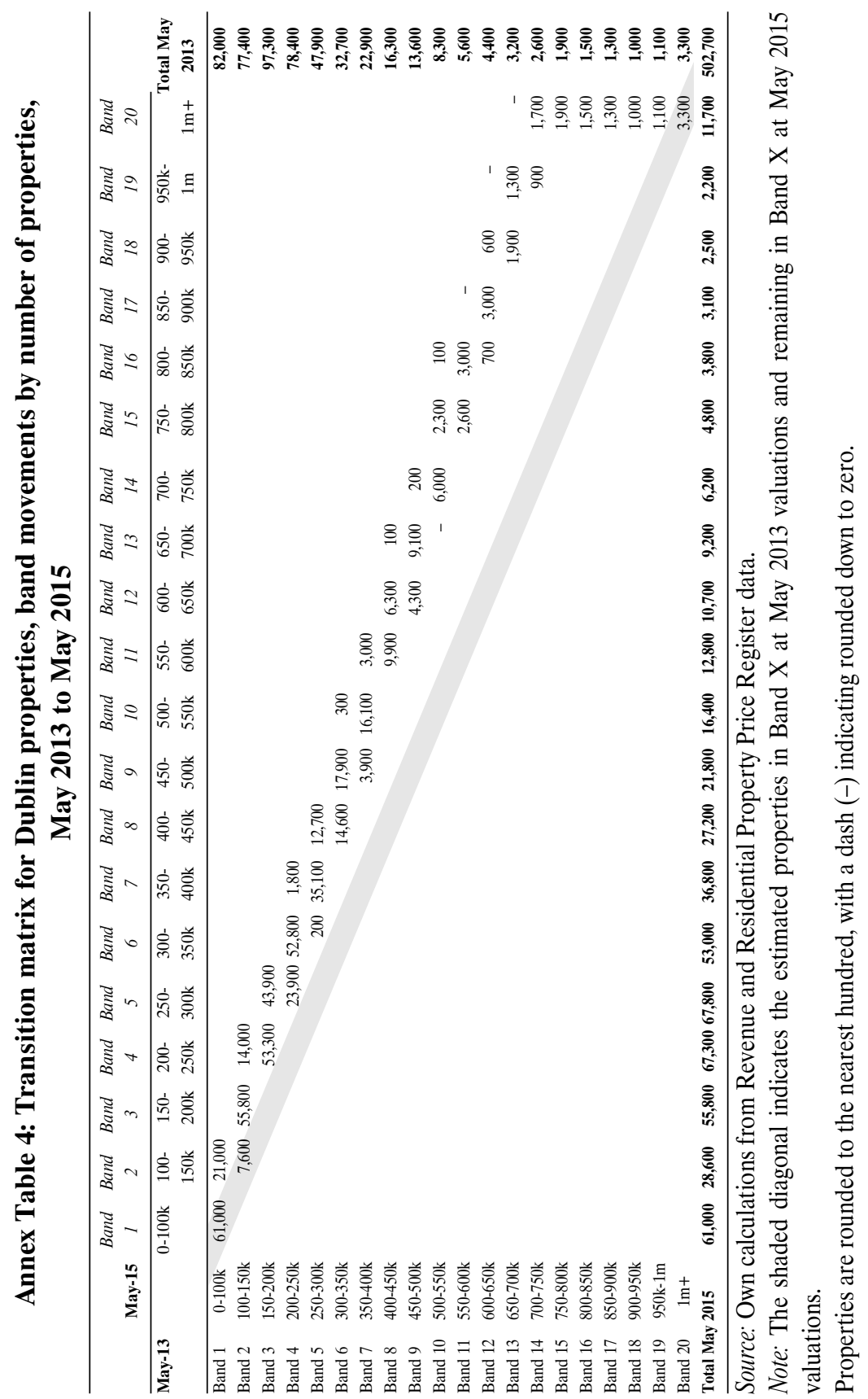




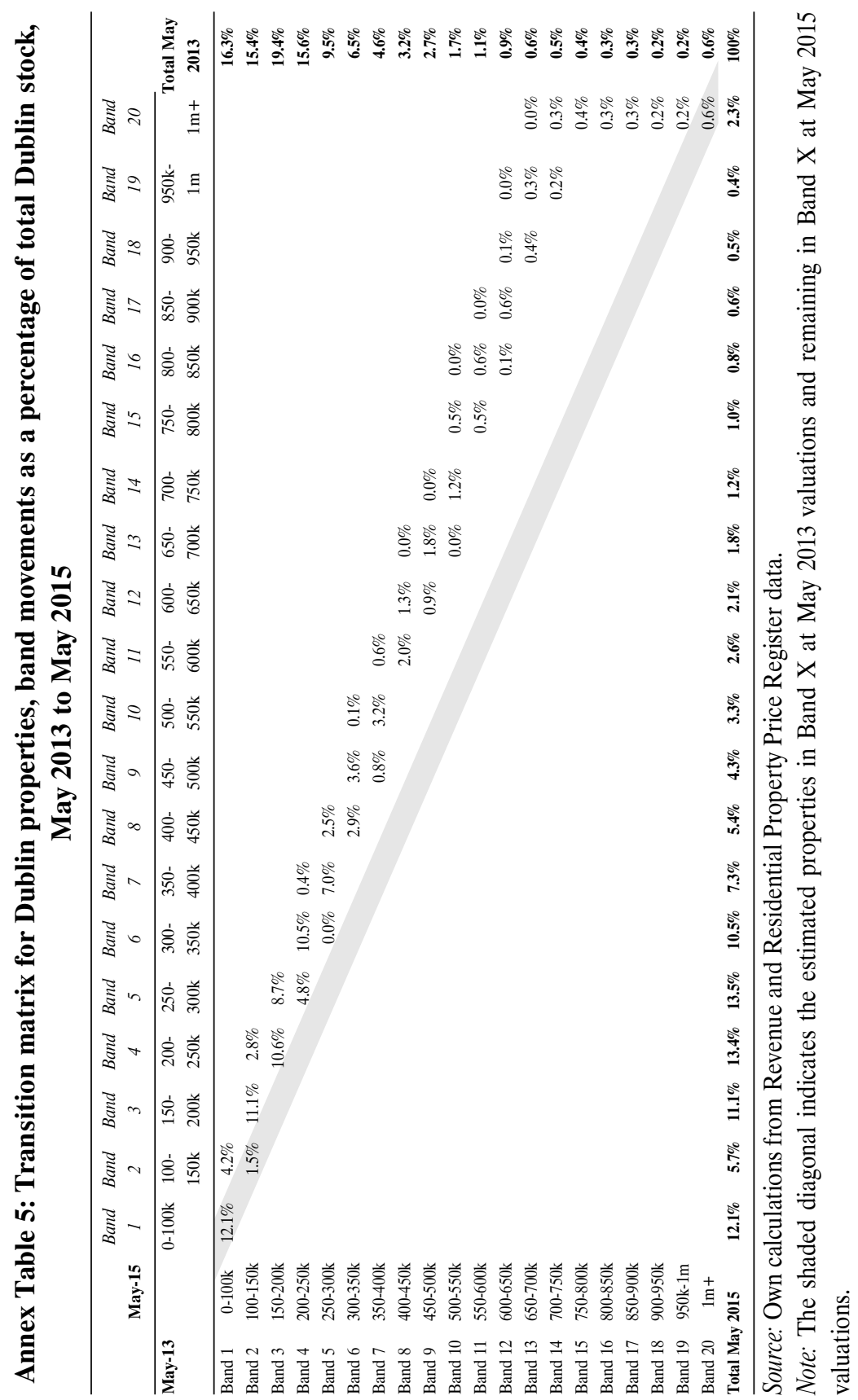




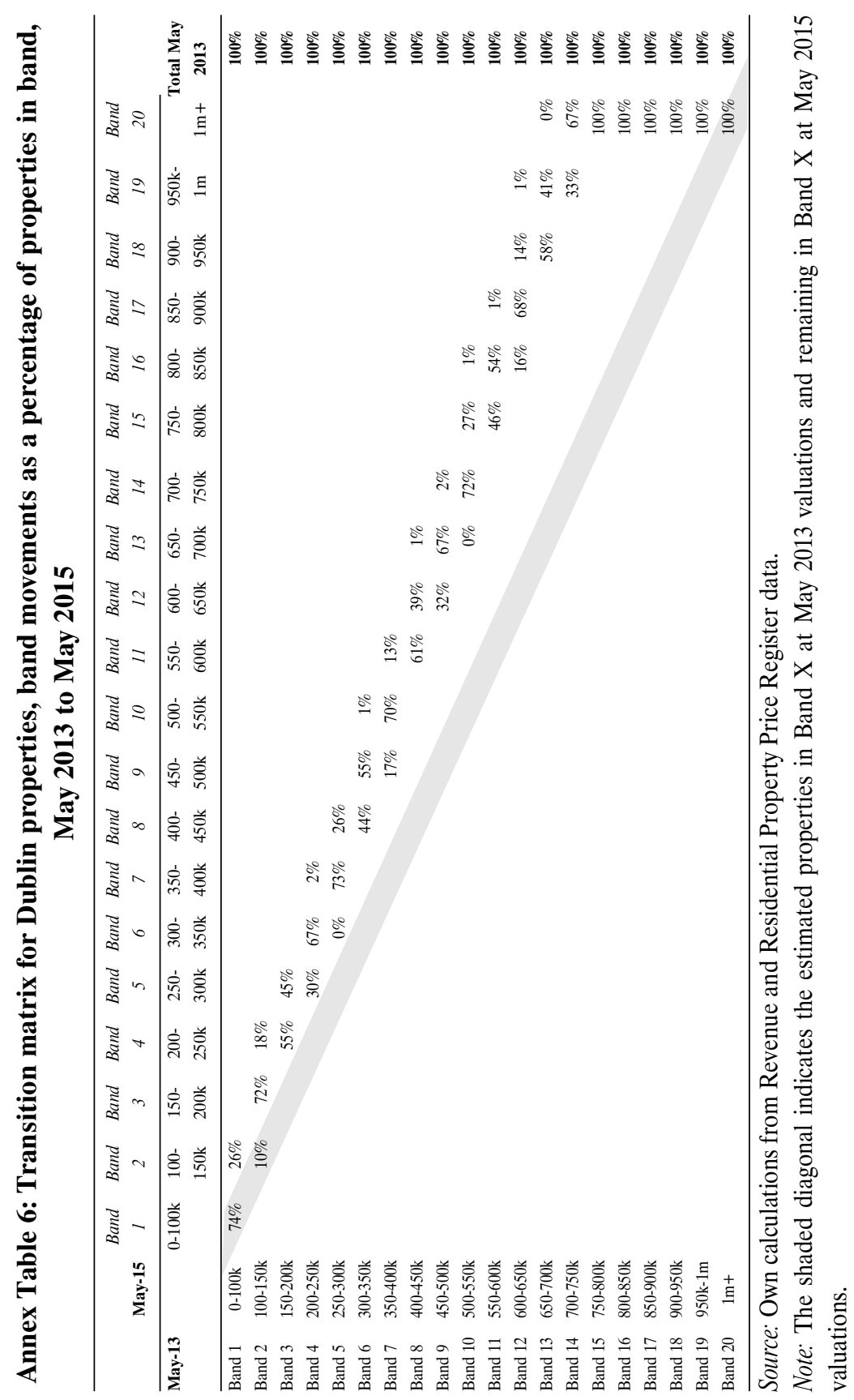




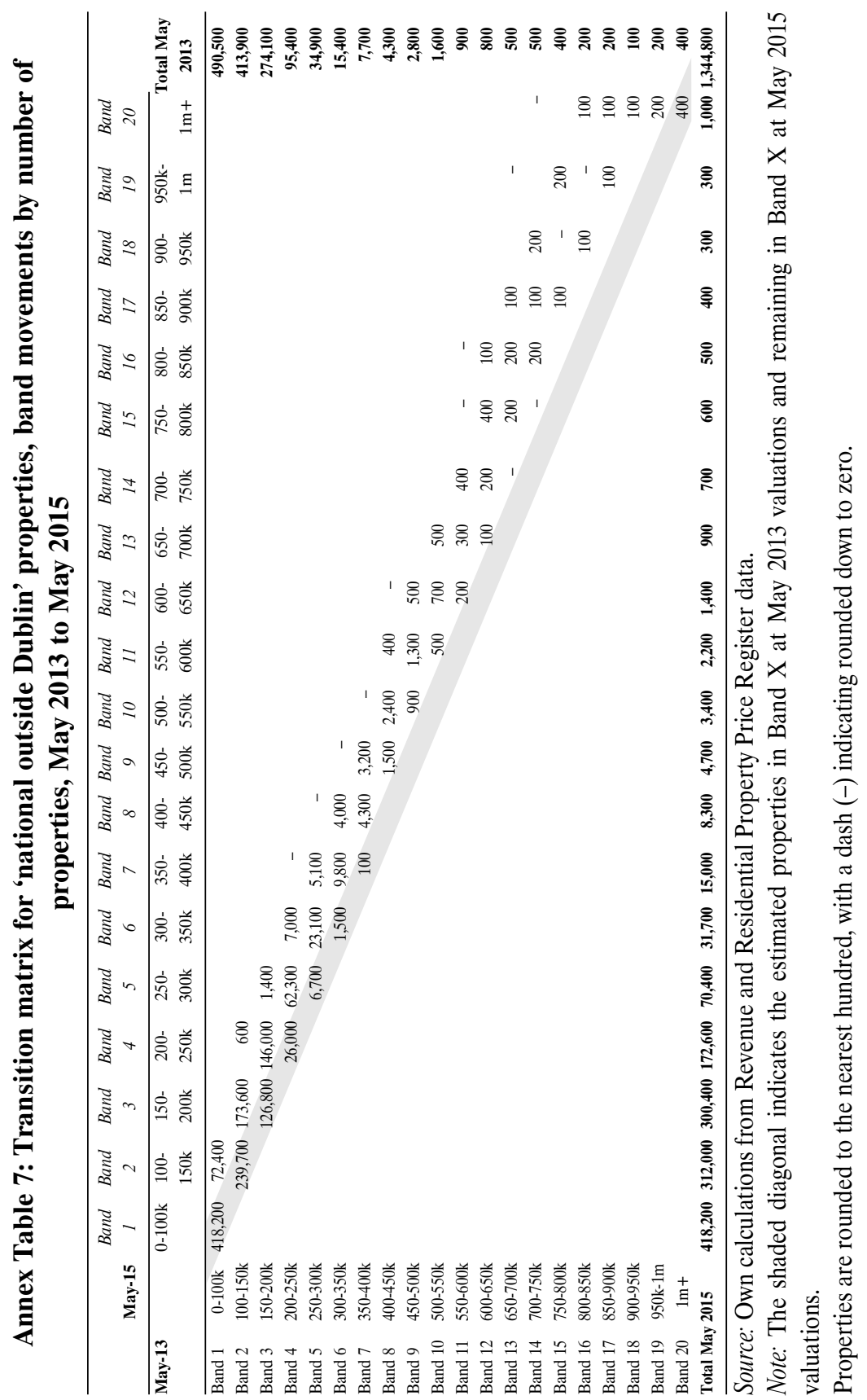




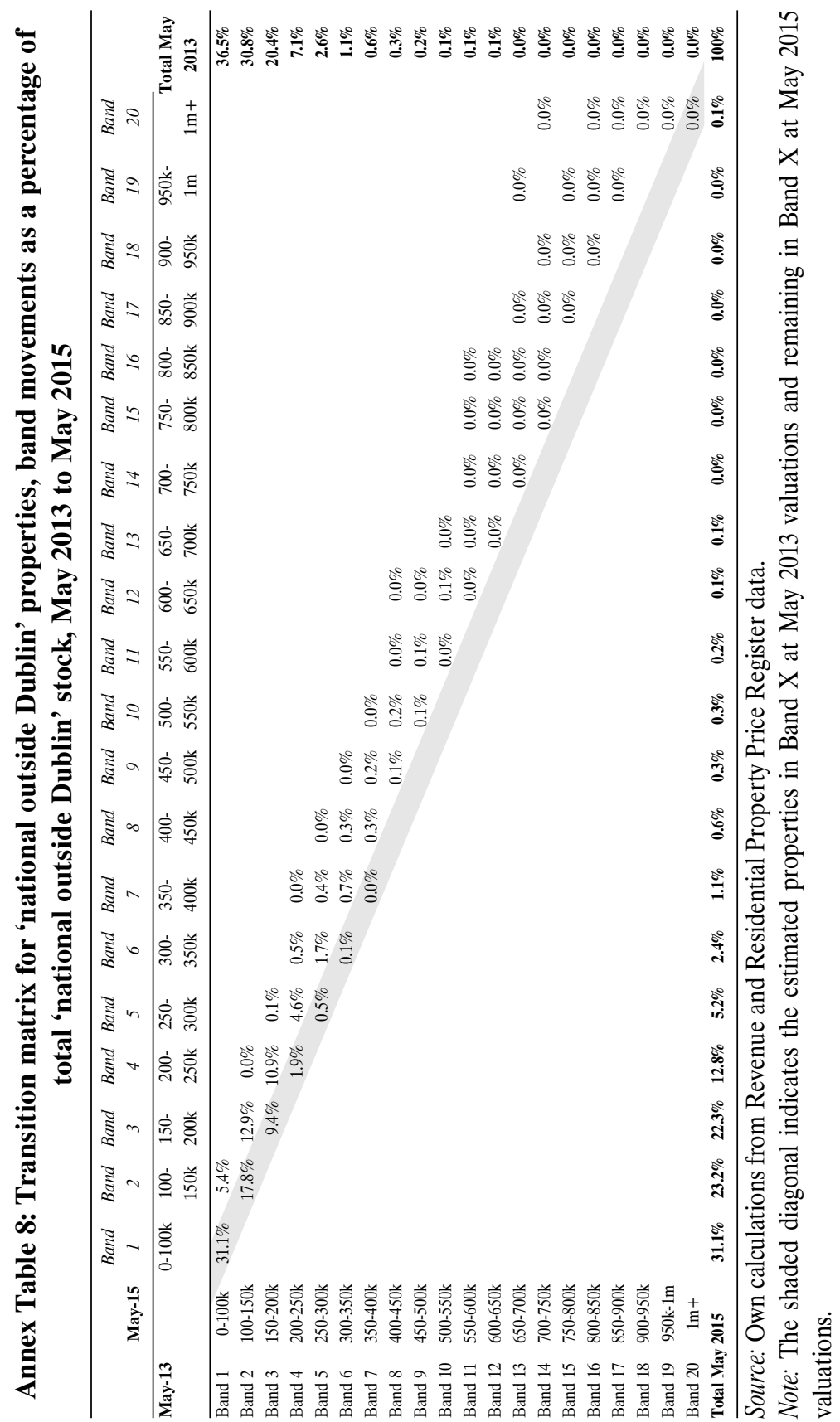




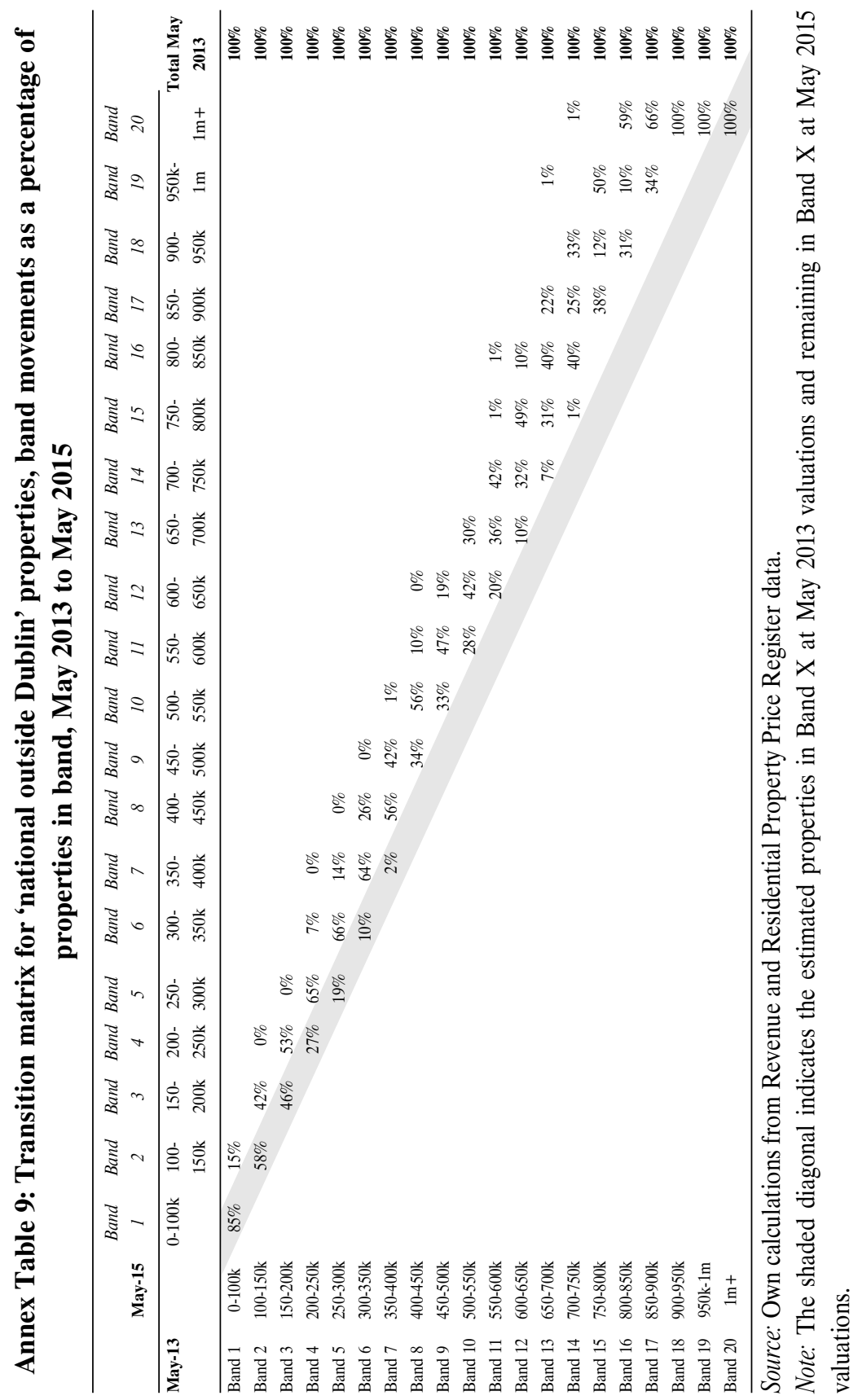




\section{Acknowledgements}

The research formed part of the Review of the Local Property Tax (LPT) (Thornhill, 2015). The authors would like to extend their thanks to David Hegarty, Gavin Murphy of the Department of Finance, Keith Walsh of the Revenue Commissioners, and to two anonymous referees, for their valuable comments.

\section{References}

Daft.ie (2012). The Daft.ie analysis of the Residential Property Price Register 2012 Q3. Retrieved from http://www.ronanlyons.com/wp-content/uploads/2012/ 10/daft-ie_rppr_research.pdf [27 March 2016].

Revenue. (2015). Local Property Tax (LPT) statistics. Preliminary. 22nd April 2015. Retrieved from www.revenue.ie [27 March 2016].

Thornhill, D. (2015). Review of the Local Property Tax (LPT). Retrieved from http://www.budget.gov.ie/Budgets/2016/Documents/Review_of_Local_Pro perty_Tax_pub.pdf [27 March 2016]. 